\title{
Introduction of a Digital Logic Project in a First-Year Honors Engineering Course
}

\section{Dr. Diana G. de la Rosa-Pohl, University of Houston (CoE)}

Diana de la Rosa-Pohl is an instructor in the Cullen College of Engineering at the University of Houston. She developed the first-year experience for the Honors Engineering Program and also teaches the twocourse sequence. Her research interests include project-based learning in engineering education and the alignment of engineering education with professional practice.

\section{Dr. Stuart A. Long, University of Houston (CoE)}

Stuart A. Long was born in Philadelphia, Pennsylvania on March 6, 1945 and completed his secondary education in Snyder, Texas. He was granted the B.A. (magna cum laude) and M.E.E. degrees in Electrical Engineering from Rice University, Houston, Texas, in 1967 and 1968, respectively, and the Ph.D. degree in Applied Physics from Harvard University, Cambridge, Massachusetts, in 1974. He was employed as an Aerosystems Engineer in the antenna design group of General Dynamics, Ft. Worth, Texas, from 1968 to 1969. From 1970 to 1974 he was a Teaching Fellow and Research Assistant in applied mathematics and applied physics at Harvard University. He was also a Research Assistant at Los Alamos Scientific Laboratories, Los Alamos, New Mexico, for the summers of 1970 and 1971. In 1974 he joined the faculty at the University of Houston, and served as Chairman of the Department of Electrical and Computer Engineering from 1984 to 1995 and from 1998 to 1999 and as Associate Dean of the College of Engineering from 1995 to 1998, and again from 2000 to 2008. He was Interim Dean of the Honors College in 200809. He also serves as Associate Dean of Undergraduate Research and the Honors College, and in this role oversees the undergraduate research programs for the entire campus. He is a Professor in the Department of Electrical and Computer Engineering and a registered Professional Engineer. In 2010-2011 he served as Interim Vice Chancellor/Vice President for Research and Technology Transfer. His research interests are in the broad area of applied electromagnetics and more specifically in microstrip and dielectric resonator antennas. His most recent work has been focused on broadband dielectric resonator antennas and on the use of existing structures to serve as radiators for wireless communications systems. Over the past several years Dr. Long has also begun a program designed to increase the number of graduates in engineering. Among these are GRADE Camps which bring high school girls to campus during the summer, the RET program which allows high school teachers to be involved in research, the REU program which involves undergraduates in research activities, the WIE-UH program which forms a community for female engineering students, and Redshirt Camps that aid in the retention of currently enrolled students. These programs are sponsored by NSF and the State of Texas.

\section{Ms. Casey Goodwin, University of Houston Honors Engineering Program}

Casey Goodwin is a senior mechanical engineering student at the University of Houston, graduating in May 2013. She is performing undergraduate research with Dr. de la Rosa-Pohl in the area of engineering education. 


\section{Introduction of a Digital Logic Project in a First-Year Honors ENGINEERING COURSE}

\section{Introduction}

The honors engineering program at the University of Houston was officially established in the fall of 2009 as a way to bring the college's top engineering students together into a community which fostered camaraderie and professional identity. Although the college had offered an honors course in the freshman year before, 2009 marked the first year that the completely project-based first-year experience was included in the curriculum. The first author developed this two-course sequence by experimenting with more advanced technical projects than had previously been implemented in the freshman year. The intention was to give students early exposure to real-world tools of the trade. The course moved from the classroom full-time to a hybrid model of 50\% classroom lectures/demos and 50\% laboratory work. It was important to situate a significant portion of the learning in a laboratory environment so that students would immediately feel some connection to the profession.

Beginning with the spring 2011 semester, a new digital logic project was implemented as a way to introduce freshmen to computer concepts as well as advanced skills and tools used in the profession. Incoming engineering students have historically had to work through a wide array of mathematics and other theoretical courses before they obtained the knowledge and skill set necessary to complete a meaningful technical project. This wait time between when a student decided to pursue an engineering degree and when he or she had the opportunity to apply content knowledge in that major to practical projects seemed to have a negative impact on student enthusiasm and motivation to obtain their degree.

Perhaps because of this, one recent trend in engineering education has been to engage students in real-world engineering activities as soon as they arrive on campus. This potentially keeps students motivated and encourages them to persist in the program. Finding engineering projects that incoming students can succeed in is a difficult task because freshmen enter engineering programs with limited technical knowledge and skills, which in turn restricts the level of sophistication and complexity with which freshman projects can be designed. For example, many interesting and non-trivial electrical and computer engineering problems require a strong programming background or knowledge of advanced mathematics.

Digital logic, however, is an area of computer engineering that requires more transferable skills - such as critical thinking and problem-solving - than advanced theoretical knowledge. Digital logic uses discrete mathematics instead of the calculus that many students struggle with early in the engineering curriculum. Although new knowledge has to be acquired in the area of Boolean algebra, this new content is a very natural extension of the regular algebra that most engineering students are already very comfortable with. Because of this non-reliance on calculus, digital logic projects make prime candidates for introducing new engineering students to authentic engineering activities and the use of professional instruments and tools. 
But why include such a computer engineering heavy project in a class when most students are not even electrical engineering students? It is true that most students in this freshman cohort would never see or use this material again in later courses. That is precisely why the first author felt it extremely important to develop such a project as the one described in this paper. It had become more apparent each semester that the newer classes of incoming students who grew up in a world of solid-state devices and a culture of point-and-click were entering college with almost no knowledge of the inner workings of the hardware that they were so accustomed to using. These younger students were becoming master users of technology but had almost no knowledge about how things actually worked. And yet, every one of these students was about to spend a large portion of their next four years of school working on computers and even programming them without knowing much about how their programs translated into operations and results. That is how the idea was hatched to create a real-world hands-on project that would tie software to hardware and provide insight into how voltage and current provide the basis for all computer information processing. The fact that most of the material covered would not be reinforced in later classes for all but a few electrical and computer engineering students was even more reason to introduce this project early in this multidisciplinary setting. However, it was uncertain how such an involved electrical engineering-centric project would be received within a multidisciplinary group of students. It was also uncertain as to whether the students at this level were even capable of mastering the concepts, even though they were all honors students. Being an all honors group gave them a slight advantage for success, but this material was typically covered years later in the electrical engineering curriculum and projects of this complexity had not been attempted before in the freshman year.

\section{Research Question}

The researchers for this study were interested in determining whether it was appropriate to introduce digital logic theory so early (or even at all) in the engineering honors curriculum. There was a concern that the content would be demotivating for students of majors other than electrical and computer engineering (ECE). The honors courses in this study included engineering freshmen from almost all disciplines in the college of engineering (with the exception of industrial engineering majors who take a different version of the course). The researchers were concerned that students from disciplines other than ECE would not find the content relevant to engineering and hence the course might have the opposite of the intended effects. Therefore, the research question for this study was: "What is the impact of introducing a digital logic project in a first-year honors engineering curriculum?"

\section{Significance}

Having students work on significant and meaningful projects in the freshman year ties them very early to the profession, which may help to retain them in the engineering program. Historically, these first-year courses have been more personal development than technical development, and students have failed to find the relevance of the material studied to their chosen field. By using projects such as the one described in this paper, students might become more engaged and challenged in the program and hence more motivated to persist through graduation. Finding early evidence of this type of engagement and student success is an important first step for later retention studies. 
It is also important to study how this type of ECE-centric project impacts students in non-ECE disciplines. ECE students can easily see the relevance of digital logic theory to their field, and that perceived relevance can increase their sense of professional identity and have a positive impact on their motivation to persist. However, non-ECE students may not be able to make those same connections and that could negatively impact their sense of community with the rest of group and their sense of engagement with the profession. If a project is negatively impacting a majority of the students on intended course outcomes, then clearly a different approach must be taken.

This paper describes the methods used to implement a digital logic design project in the firstyear honors engineering curriculum and presents the quantitative and qualitative results obtained from the assessment of project objectives through project grades, exam results, and student survey responses.

\section{Literature Review}

\section{Historical Location of Boolean Algebra and Karnaugh Maps in Engineering Curriculum}

Digital logic concepts have historically been taught to electrical and computer engineering students deep in the engineering curriculum. For example, the introductory logic design course at Santa Clara University has been taught at the end of the sophomore year or beginning of the junior year ${ }^{1}$. At Bucknell University, digital logic concepts have been taught at the beginning of the junior year ${ }^{2}$. And at Auburn University, students have learned about simple logic circuits, binary arithmetic, and adder circuits in laboratories during the sophomore year ${ }^{3}$.

This late placement of digital logic theory, after the calculus-based analog electronics courses, has been prevalent in engineering colleges despite the fact that, as Cordes et al noted, "discrete mathematics provides much more useful domain knowledge for our students [than does calculus], and early exposure to this material should promote a better understanding of fundamental computer science and engineering concepts" ${ }^{4}$. It is probably no coincidence that the analog-then-digital course sequence follows the historical development of these fields. Digital electronics and their computer applications are relatively new fields in electrical engineering. So it is perhaps not surprising that Cordes et al also noted that they knew of no other curriculum at that time (other than the one they developed at the University of Alabama) where discrete math was taught before calculus ${ }^{4}$.

Even now, sixteen years later, the calculus-before-discrete-math model is still the standard in engineering education. However, some institutions have over the years introduced freshmanlevel, hands-on courses into their electrical and computer engineering curricula that cover digital logic concepts. For example, in the early 1990s, USC offered a course titled EE101: Introduction to Digital Logic, which was taught to electrical engineering students during their first semester. The course emphasized Boolean algebra, number systems, and binary arithmetic ${ }^{5}$. The University of Illinois at Urbana-Champaign constructed an electrical engineering course offered to students during their freshman year that covered topics including logic gates and Boolean Algebra ${ }^{6}$. The University of Alabama's first-semester freshman-year course covered binary 
systems and Boolean algebra ${ }^{4}$. Portland State University offered a digital circuits course taken by electrical engineering students during the first quarter of their freshman year. In the first week of this course, students learned about logic gate symbols, truth tables, and Boolean expressions ${ }^{7}$. By the fourth week, students had learned how to design combinatorial logic circuits using Boolean algebra and Karnaugh maps. Arizona State University recently added a freshman-level introductory digital logic course to its curriculum as well ${ }^{8}$.

These courses were all meant to give beginning electrical and computer engineering students hands-on engineering experiences that would hopefully engage them and retain them in the program. However, these offerings were limited to electrical and computer engineering departments. For students who were not majoring in computer or electrical engineering, the basics of Boolean algebra, numbering systems, and digital logic were often never learned or were learned late in the curriculum. For example, the mechanical engineering department here at the University of Houston currently does not require a course that introduces the basics of digital logic design. And although the mechanical engineering department at Colorado State University has in the past offered a course as part of its core curriculum called Mechatronics and Measurement Systems (which provided an introduction to digital electronics and discrete mathematics, among other things), that course was designed as a junior-level course ${ }^{9}$.

\section{Student Impact}

Universities that have offered this sort of traditionally upper-level engineering experience to first-year engineering students have claimed that these courses impacted students in a wide array of positive ways, which included both affective and cognitive outcomes. Affective outcomes include student enthusiasm for engineering, their commitment to their major, their engineering self-confidence, student perception of faculty involvement and how they perceive the relevance of the courses that they are studying. Cognitive outcomes are more concrete and include student achievement and preparation. Evidence of both types of outcomes is presented in the following sections.

\section{Affective Outcomes}

Enthusiasm. With regards to the impact of the first-year engineering course at Carnegie Mellon University, Director et al observed that entering students were enthusiastic about starting "real engineering classes" in their first semester ${ }^{10}$. They appreciated the ability to choose this type of course early in the curriculum.

At Portland State University it was observed that allowing students to use "industrial strength" tools early in their engineering academic career "generate[d] sufficient enthusiasm to overcome any pain encountered during the initial learning curve and in most cases create[d] a sizable appetite for further work" 7 . This is clearly a huge advantage for students in a major that sees a large attrition rate in the first two years.

A detailed study at Arizona State University (ASU) reported the impact of a freshman digital design course on persistence in engineering and student motivational orientation ${ }^{8}$. The authors administered pre- and post-surveys including selected items from the Persistence in Engineering (PIE) survey instrument ${ }^{11}$. Students were also given the ability to provide additional comments 
on the course. The survey revealed that ASU's course "had no significant impact on the motivation for taking more engineering courses or becoming an engineer after graduation" 8 . However, the initial values were all very high indicating that the course was not a significantly demotivating factor for students either. Also, additional student comments showed that the students found the course to be very interesting and "provided deep insight into the functioning of electrical and computer systems" 8 , suggesting that students valued and were enthusiastic about the course. From these different studies, it seems clear that students who are able to learn practical, hands-on engineering skills during their freshman year are eager to do so.

Commitment and self-confidence. Another observed benefit of this type of hands-on freshmanlevel experience is that it seems to help students determine if they have picked the right major ${ }^{10}$. It is hoped that, if the introductory courses engage students early enough, they will have more commitment to their chosen major during their harder sophomore- and junior-level classes. Hall ${ }^{7}$ theorized that working on hands-on projects during a students' freshman year "helps a student develop the perseverance and self-confidence needed to succeed in an engineering program and as an engineer" 7 . A student's self-confidence about his or her engineering skills is a key component to success while pursuing their engineering education and while pursuing a postgraduation career. Alciatore and Histand ${ }^{9}$ observed of their junior-level mechanical engineering students that, while they were often initially intimidated by difficult projects and subjects introduced in his class, "their self-confidence [rose] with each successful exercise they complete[d]" 9 .

Attention Paid to Students. While a student's involvement with the engineering administration and faculty is important to his or her academic success, so too is a student's perception of his or her professors' involvement with the student. Involved, hands-on laboratory exercises such as the ones that are increasingly being used in entry-level freshman classes lead professors and teaching assistants to engage with them. This is something students appreciate, especially freshmen who are often not especially engaged with their engineering departments ${ }^{10}$. In Reisslen et al.'s ${ }^{8}$ survey of freshman students who had taken a hands-on laboratory sequence, many of the only survey questions that showed significant differences were ones relating to their interactions with the professor and teaching assistant. Students rated their opportunities to interact with both professor and teaching assistants higher after having taken the class than before.

Relevance of Mathematics. Perhaps the only negative consequence of teaching a course emphasizing Boolean algebra to freshman engineering students was recorded by Reisslen et al ${ }^{8}$. They found that, since Boolean algebra relatively simple compared to calculus, it led to a decrease in student perception of relevance of mathematics to engineering. No research determining the long-term impact of this misperception could be found.

\section{Cognitive Outcomes}

While engineering student outcomes such as confidence, commitment, and enthusiasm are clearly beneficial, the cognitive benefits of offering practical, hands-on courses covering topics like Boolean algebra and digital logic are also undeniable.

Academic Preparation. Several of the studies in the literature found that the hands-on entrylevel engineering courses described above benefit students as they continue on their academic 
careers, preparing them for the content and difficulty levels of future courses. For example, some students commented that they felt the introductory course "provided deep insight into the functioning of electrical and computer systems", saying it "was a good foundation for further study in electrical and computer science and engineering" 8 . Another researcher had his students perform, by hand, complicated digital logic mapping methods like Karnaugh maps, and noted that "[a]lthough students will later use computer-based tools to optimize and implement combinational logic circuits, knowledge of these topics helps students understand computergenerated results and in some cases guide the computer to a more optimal solution" 7 . The vast majority (75-90 percent) of electrical and computer engineering students at Auburn University rated their sophomore- and junior-level laboratory sequences as contributing to their academic growth; they gave similarly high ratings to the labs' contributions to their practical skills and theoretical knowledge ${ }^{3}$.

Career Preparation. Another advantage of hands-on, practical engineering application classes for freshman engineering students is that the students start developing the skill sets needed for professional work early on in their academic careers. Some companies have even offered these students engineering internships for the summer following their freshman year ${ }^{10}$. The practice of providing students with industry experience so early in their academic careers is a major achievement since these opportunities were generally reserved for sophomore or junior students. Puvvada and Breuer also noted that the skills and programs students learned in their hands-on classes were sure to be an asset on the job ${ }^{5}$.

\section{Methods}

A new digital logic project was introduced into the honors engineering program's first-year curriculum at the University of Houston to introduce second-semester engineering freshmen to a practical engineering project. This project was introduced at the beginning of the second course in a two-course series of introductory engineering classes that honors engineering students take during their first year. The purpose of this course, ENG 1331H: Introduction to Computing for Engineers, was to introduce engineering students from various majors to the basics of how computers work and how to use them as tools to solve engineering problems. The first course in the sequence, ENG 1100H: Introduction to Engineering, taught students the basic tools of the engineering discipline and gave them background on some of the different challenges engineers may encounter. Both ENG $1100 \mathrm{H}$ and ENG $1331 \mathrm{H}$ were project-based courses. Throughout both semesters, students were assigned a variety of group projects, all of which were completed in randomly assigned teams. For the digital logic project, students were assigned to teams of twoneither a students' major nor his or her level of ability had any impact on who he or she was partnered with. Both courses met for an hour and a half twice each week; generally, lectures were given on Tuesday to provide background on the current project and then students were required to work on the project in an electronics lab during class time on Thursdays. If students needed additional lab time to work on their project, they were encouraged to go to the lab during one of the four teaching assistants' lab hours. Table 1 shows the class schedule followed during the first semester that the digital logic project was introduced (spring 2011). Note that only the first six weeks of the course schedule are shown, because that is the time period when the digital logic project was introduced, taught, and worked on by the students. 
Table 1: ENG 1331H curriculum for the first six weeks of the spring 2011 semester, the interval where students worked on the digital logic/calculator project.

\begin{tabular}{|c|l|l|l|}
\hline Week & & & \\
\hline $\mathbf{1}$ & Date: & Tuesday, January 18, 2011 & Thursday, January 20, 2011 \\
\hline & Topic: & Course Intro., Computer Basics & Discrete Logic Devices (AND, OR, NOT) \\
\hline & Location: & Classroom & Classroom \\
\hline $\mathbf{2}$ & Date: & Tuesday, January 25, 2011 & Thursday, January 27, 2011 \\
\hline & Topic: & Numbering Systems, Binary Logic & Switches \& LED's Revisited, Binary Circuits \\
\hline & Location: & Classroom & Lab \\
\hline $\mathbf{3}$ & Date: & Tuesday, February 01, 2011 & Thursday, February 03, 2011 \\
\hline & Topic: & Computer Math (ALUs), Karnaugh Maps & ALU Work Day \\
\hline & Location: & Classroom & Lab \\
\hline $\mathbf{4}$ & Date: & Tuesday, February 08, 2011 & Thursday, February 10, 2011 \\
\hline & Topic: & Operating Systems & ALU Work Day \\
\hline & Location: & Classroom & Lab \\
\hline $\mathbf{5}$ & Date: & Tuesday, February 15, 2011 & Thursday, February 17, 2011 \\
\hline & Topic: & Networks, Protocols & ALU Work Day \\
\hline & Location: & Classroom & Lab \\
\hline $\mathbf{6}$ & Date: & Tuesday, February 22, 2011 & Thursday, February 24, 2011 \\
\hline & Topic: & EXAM 1: Computer Basics & ALU Work Day \\
\hline & Location: & Classroom & Lab \\
\hline
\end{tabular}

In order to accomplish the required tasks associated with the digital logic project, students were taught the basics of numbering systems, Karnaugh maps, Boolean algebra, and discrete logic devices during class lectures. They were taken through the entire design process of creating a simple two-bit input/six-bit output binary calculator (or simple arithmetic logic unit-ALU). The minimum requirement for full credit was correct operation of two out of four elementary mathematical operations; the options being addition, subtraction, multiplication and division. While the project as a whole was undeniably a sophisticated engineering project that required critical thinking and problem solving skills, its building blocks all utilized concepts that freshman students were able to learn without the need of any advanced mathematical or theoretical circuit knowledge.

\section{Data}

The participants in this study were the 41 and 47 freshman engineering honors students enrolled in ENGI 1331H in the spring of 2011 and the spring 2012 respectively. In order to answer the research question for this study, the authors used the results of a midterm exam covering skills related to digital logic design, as well as both qualitative and quantitative responses from an endof-course survey. The percentages of students that completed the basic project requirements and bonus operations were also observed.

The midterm measured the students' ability to comprehend the basic theory of digital logic design. There was initial concern that non-ECE students in the class would not be motivated enough to work at mastering the skills necessary to complete the project and that those low grades would bring the class mastery numbers down. By looking at mastery levels for each topic 
individually, overall class comprehension on particular skills as well as problem areas could be easily identified.

The end-of-course class survey provided insight into the students' perception of relevance of the material and overall enjoyment of the projects and the class. Again, because of the general ECE nature of the course content, the instructor wanted to be sure that the project was not lowering the motivation of students and their commitment to persist in engineering.

\section{Procedures}

All students were taught the basics of digital logic in class and then assigned a project in which they had to design (using truth tables, Karnaugh maps, and circuit diagrams) a simple two-bit input binary calculator (or ALU, in the context of the project). Students were assigned to groups of two for the duration of the project. The entire project lasted six weeks.

During the digital logic project, students were taken through the entire design cycle. The starting point for the project was a simple list of binary instructions that needed to be hard coded in the circuit. Table 2 shows the different instruction "types" included in the instruction set. The instruction set covered all possible instructions for addition, subtraction, multiplication, and division, as well as the desired output for each instruction. Students used this document to begin the design process. Using these instructions, they created the respective Karnaugh maps for each of the 6 output bits of the simple ALU. From those Karnaugh maps, the students could derive the minimized Boolean equations for each output bit. Circuit diagrams were then developed for each equation and then circuits built from those diagrams.

Table 2. Instruction "Types" for ALU Project

\begin{tabular}{|c|c|c|c|c|c|c|c|c|c|c|c|c|}
\hline & \multicolumn{2}{|c|}{ Op Code } & \multicolumn{2}{|c|}{ In1 } & \multicolumn{2}{|c|}{ In 2} & \multicolumn{6}{|c|}{ Output } \\
\hline & i5 & $\mathrm{i} 4$ & i3 & i2 & i1 & i0 & o5 & o4 & $\mathrm{o} 3$ & $\mathrm{o} 2$ & o1 & $\mathrm{o} 0$ \\
\hline ADD & 0 & 0 & \multicolumn{2}{|c|}{ Operand 1} & \multicolumn{2}{|c|}{ Operand 2} & \multicolumn{6}{|c|}{ Result } \\
\hline SUB & 0 & 1 & \multicolumn{2}{|c|}{ Operand 1} & \multicolumn{2}{|c|}{ Operand 2} & \multicolumn{6}{|c|}{ Result } \\
\hline MUL & 1 & 0 & \multicolumn{2}{|c|}{ Operand 1} & \multicolumn{2}{|c|}{ Operand 2} & \multicolumn{6}{|c|}{ Result } \\
\hline DIV & 1 & 1 & \multicolumn{2}{|c|}{ Operand 1} & \multicolumn{2}{|c|}{ Operand 2} & Error & \multicolumn{5}{|c|}{ Result } \\
\hline
\end{tabular}

In order to better modularize the project for testing and grading, each operation (addition, subtraction, multiplication, and division) was designed and built separately. This led to a much larger circuit in the end than necessary, but it made the design process simpler and allowed the process to be broken down into a series of manageable steps for students. It also allowed for easier debugging of the circuit by teaching assistants along the way. Therefore, parallel circuits for each operation were built and different operations were selected by wiring the instruction opcodes through a multiplexer at the end. The completed circuit was built using only AND, OR, and NOT (inverter) ICs along with 2-to-1 or 4-to-1 multiplexers (depending on how many 
operations were completed). Therefore the circuit was completely combinational and no knowledge of flip-flops or state machines was required for this project.

Data Collection. Project data was collected for each team of two students. Students worked during and outside of class with their partners in an electronics lab equipped with National Instruments ELVIS stations and the ELVIS software suite. The completed hardware was checked one bit at a time using the digital writer function of the ELVIS software which allowed direct writing of bits to the ELVIS board. Output bits were tested by wiring circuit outputs to the builtin LEDs on the ELVIS boards and visually decoding the binary output.

As students successfully wired each output on the board, their work was checked and documented by the course teaching assistants. The number of working operations determined the final grade. The addition operation plus any other operation was the minimum requirement for full credit. Bonus points were then awarded for each additional operation after that.

In order to obtain a grade for individual work on the project, students were given a post-project exam that covered the theoretical concepts related to the ALU project. The concepts covered on the exam included computer basics, numbering systems, truth tables, Karnaugh Maps, circuit diagrams, and Boolean algebra. While the exams for each class were slightly different, questions on each exam were matched to cover the same content at what was assumed to be the same level of difficulty.

At the end of the semester, a survey was administered to the class to collect attitude data about the entire course. Items relevant to the digital logic project were extracted for the purposes of this study. Quantitative items were recorded on a 5-point Likert scale and qualitative data was collected in the form of written responses to open-ended questions about the course.

Data Analysis. Data documenting the progress of each team (i.e., number of operations completed) was analyzed to determine if students were able to attain a level of understanding great enough to complete a project of this magnitude and sophistication at such an early stage of their engineering education. Simple completion percentages were calculated for each possible number of project operations (i.e., 0-4).

For the exam, each exam item was coded to a single theoretical category. Responses were then graded on a binary basis. The response was recorded as correct if there was enough evidence to suggest that the student understood the concept being assessed. In this way, minor errors such as copying mistakes and arithmetic errors were overlooked. Students were considered to be proficient in a given category if they answered the majority of the questions correctly for that category. The objective for the course was 80 percent proficiency for the entire class.

With regards to the course survey, the first section contained questions related to self-perception of acquired knowledge and self-efficacy of skills covered in the project. Students were asked to rate their perceived levels at the beginning of the class and at the end of the class. Overall means of these data were calculated and charted. Additional questions were asked concerning the course impact on student commitment and other attitudes. Descriptive statistics were calculated for those items as well. Finally, open-ended responses were coded on emerging themes. Responses 
related to the digital project and the overall impressions of the course were analyzed for evidence of positive results related to any affective outcomes.

\section{Results}

\section{Project Completion Percentages}

The first question on the minds of the course developers was whether or not students at the freshmen level were capable of completing a digital logic project that more closely aligned to what was being taught at the sophomore/junior level. Therefore, the first data that were analyzed were the project completion percentages for each semester. The ALU project was first implemented in the spring of 2011 with 41 engineering honors students. All students that semester were able to complete at least one operation. The first operation was required to be the addition operation. Therefore all teams were able to design and build the circuitry for the addition operation. Approximately $10 \%$ of the class was unable or unwilling to get any other operations working (Figure 1). However, to the instructor's surprise, almost a quarter of the class attempted additional operations (operations 3 and 4) for extra credit, even though most students came into the class with very little interest in electrical and computer engineering.

\section{ALU Project Completion Percentages}

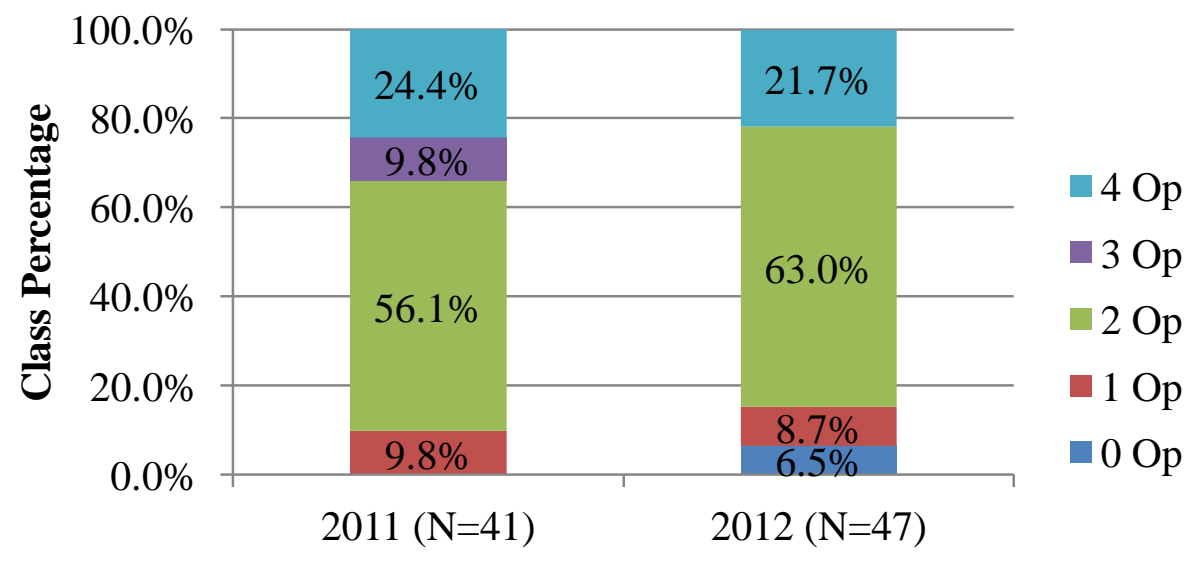

\section{Course Year (Spring)}

Figure 1. Percentage of students each year that completed $0,1,2,3$, or 4 operations of the ALU project.

The second implementation was in the spring of 2012 with a group of 47 students. During this second semester, almost $7 \%$ of the students did not complete even a single operation on the board. Another $9 \%$ were only able to complete the addition operation. Unfortunately, there is no additional data available to shed light on the reasons for this result. Because this is a freshmen class, sometimes the reason is simply that students in the first year have not yet developed good time management skills. It could also be that they did not take their work on the project very seriously and were happy with just a passing grade. It is also possible that these students were 
confused or frustrated with the material and were unmotivated to persist with the project. In future course offerings, the instructors will communicate with students to determine the reasons for the lack of progress on the project.

With respect to the concern that students at this level may not be able to accomplish the tasks on such an involved digital logic project, the figure shows very positive results. Even during the first implementation of the project, when all of the bugs were being worked out with the implementation, $90 \%$ of the students were able to meet the bare minimum of two operations and receive full credit for the project. Eighty-five percent achieved this benchmark in the second year. It does then appear that the level of this digital logic project is appropriate for first-year students (at least for the honors cohort).

\section{Exam Data}

It is one thing to be able to build a working product while working on a team, and quite another to individually master the theoretical concepts involved in designing that product. Therefore, it was not enough to analyze the project grades in order to understand whether students were grasping the digital logic concepts presented in the class. It was also necessary to obtain individual achievement grades for each concept introduced to determine if and where students were struggling with the material. Figure 2 shows the results for student exams for spring 2012. Data for the spring 2011 sections were unavailable.

\section{Percentage of Questions Answered Correctly By Students}

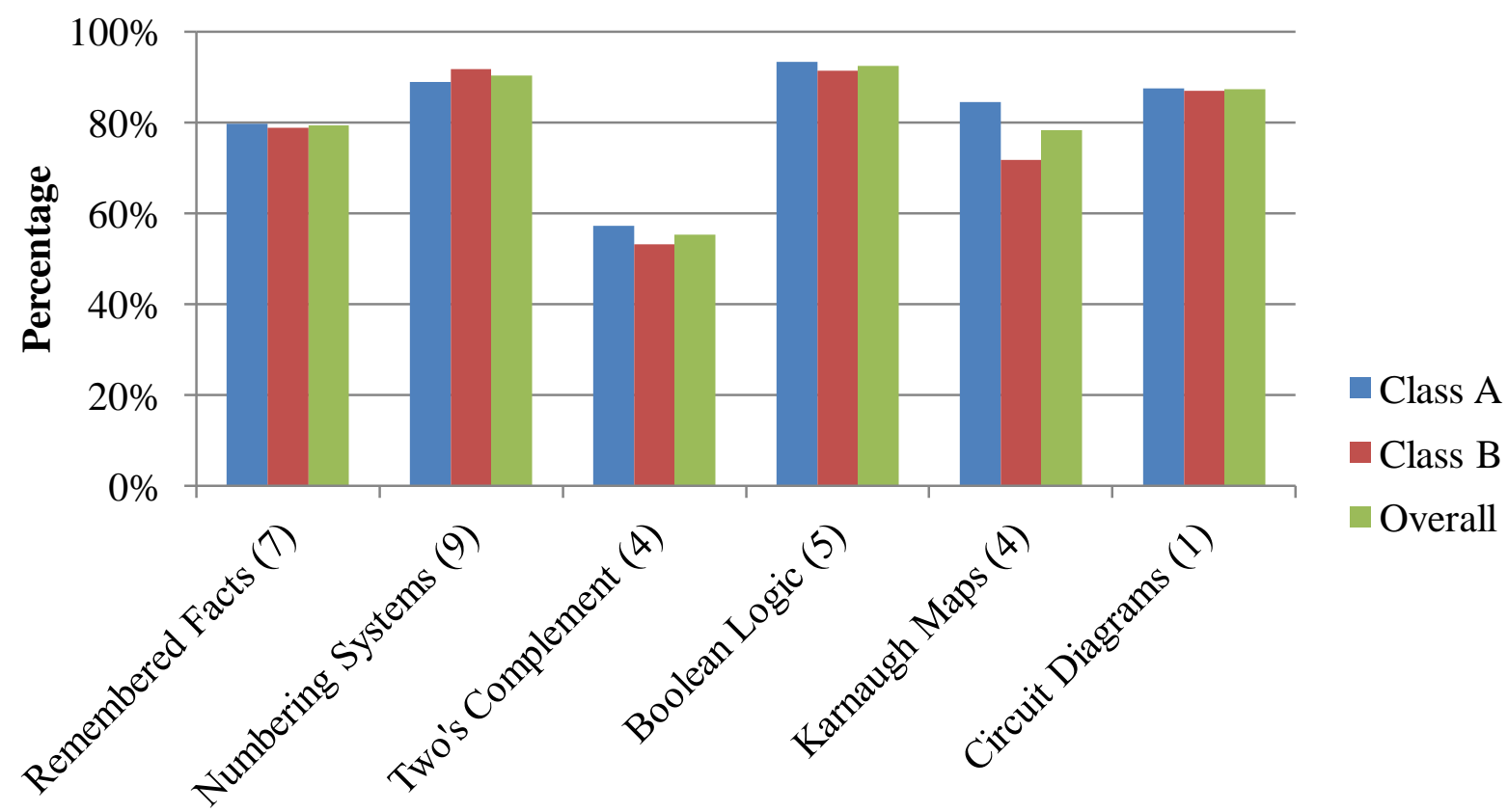

Question Type

Figure 2. Breakdown of digital logic exam content by category and percentage answered correctly by students. 
Seven of the thirty questions on the exam merely required students to remember facts presented in the notes. The remaining twenty-three questions required students to apply their knowledge at various levels of higher-order thinking. The goal for the course was $80 \%$ proficiency for each category of questions. Overall grades for the exam show that students either achieved or very nearly achieved this level for all categories of exam items except for questions related to two's complements. These results are encouraging for course instructors because they show that the students are indeed able to learn these topics very early in the curriculum. Such early exposure opens the door for engineering instructors to integrate these skills into later sophomore-level classes.

Comparing the numbers between course sections, it does appear that the exams were fairly well matched, the exception being the category of Karnaugh maps. After analyzing the questions, it was not completely obvious why one class performed so much better than the other. One theory was that one version of the problem provided more context clues than the other. Although, this could very well be the case, it is impossible to know for certain without collecting more data.

Because the topic of two's complements seemed to be an area of concern, the data was broken down further into the type of operation required by each exam item. Figure 3 shows the results of those data. Students performed relatively well on the first type of problem which required them to convert a negative two's complement number to a decimal number and then provide the absolute value. It appeared that this is the only context in which they seem to understand the concept of a two's complement. As the more subtle contexts were tested (seen in the following items) performance significantly dropped off. Therefore, it appeared that students were able to grasp the basic concept of the two's complement number representation, but more practice and feedback needed to be provided to ensure that students fully understood the concept. Changes will be made to future offering of the course to address this issue.

\section{Two's Complement Exam Items}

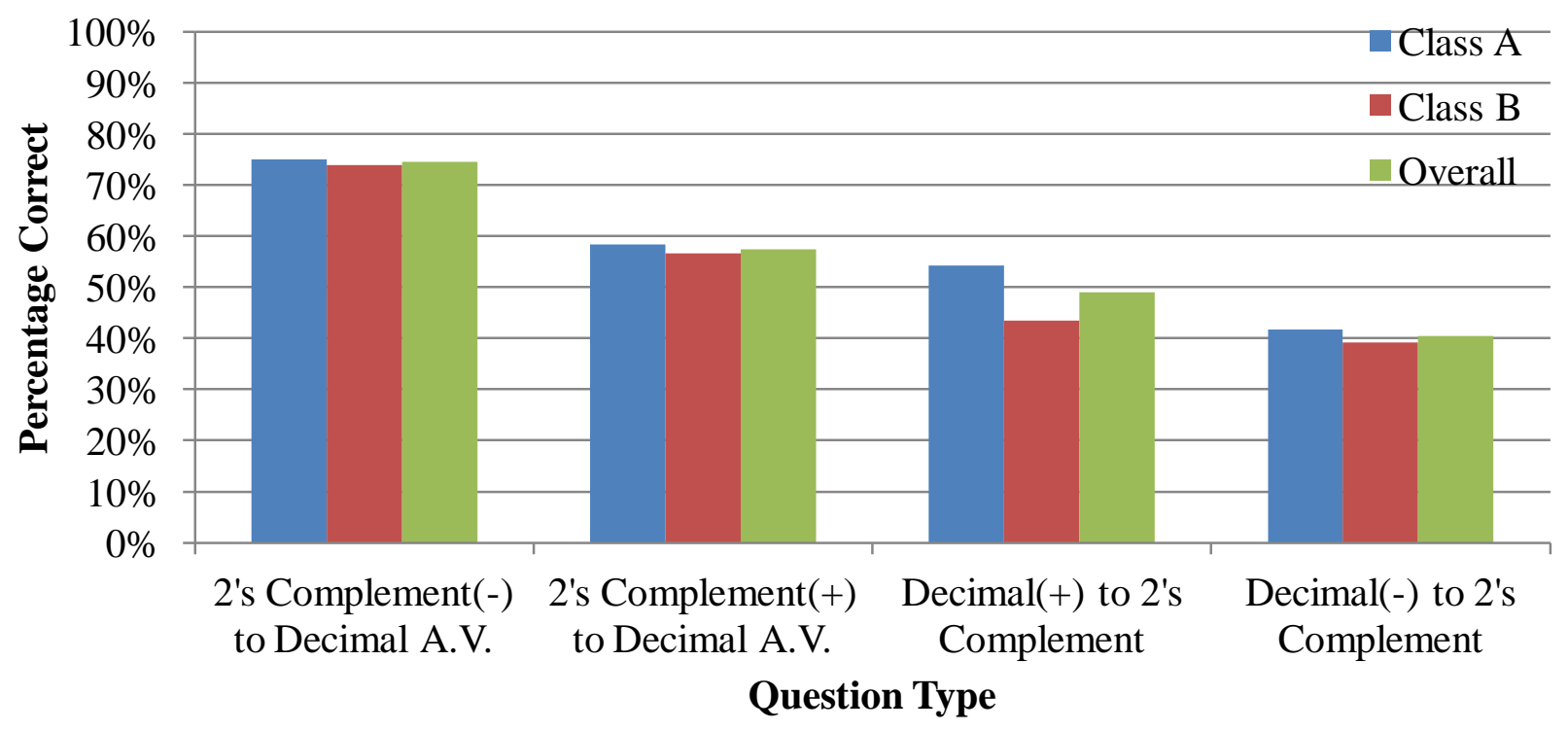

Figure 3. Mastery percentages for two's complement exam items. (A.V. = absolute value) 


\section{Survey Responses}

In addition to the content area data collected from exams, self-reported survey data was also collected for the spring 2011 group at the end of the semester. The complete survey administered to this group of students is included in Appendix A. The survey questions covered affective outcomes related to the class. Figure 4 shows the results of the self-efficacy of the students associated with skills covered in the digital logic project. Data was recorded on a five-point Likert scale with 1 being the lowest level of confidence in performing the skill and 5 being the highest. Both measures were reported by students at the end of the semester so that they could better convey their perceived change in skill level. Since most students come in with very little computer hardware knowledge, it is not surprising that initial levels were very low (between 1 and approximately 2 for all skills).

The perceived change in skill level was striking for all topics. Overall, the students felt that they had mastered all of the topics related to the project after coming in with very little knowledge. Hopefully these data will translate into a sense of accomplishment and increased professional identity within the group as they start to feel that they are acquiring real-world skills.

\section{Confidence in Performing Digital Electronic Skills (Spring 2011)}

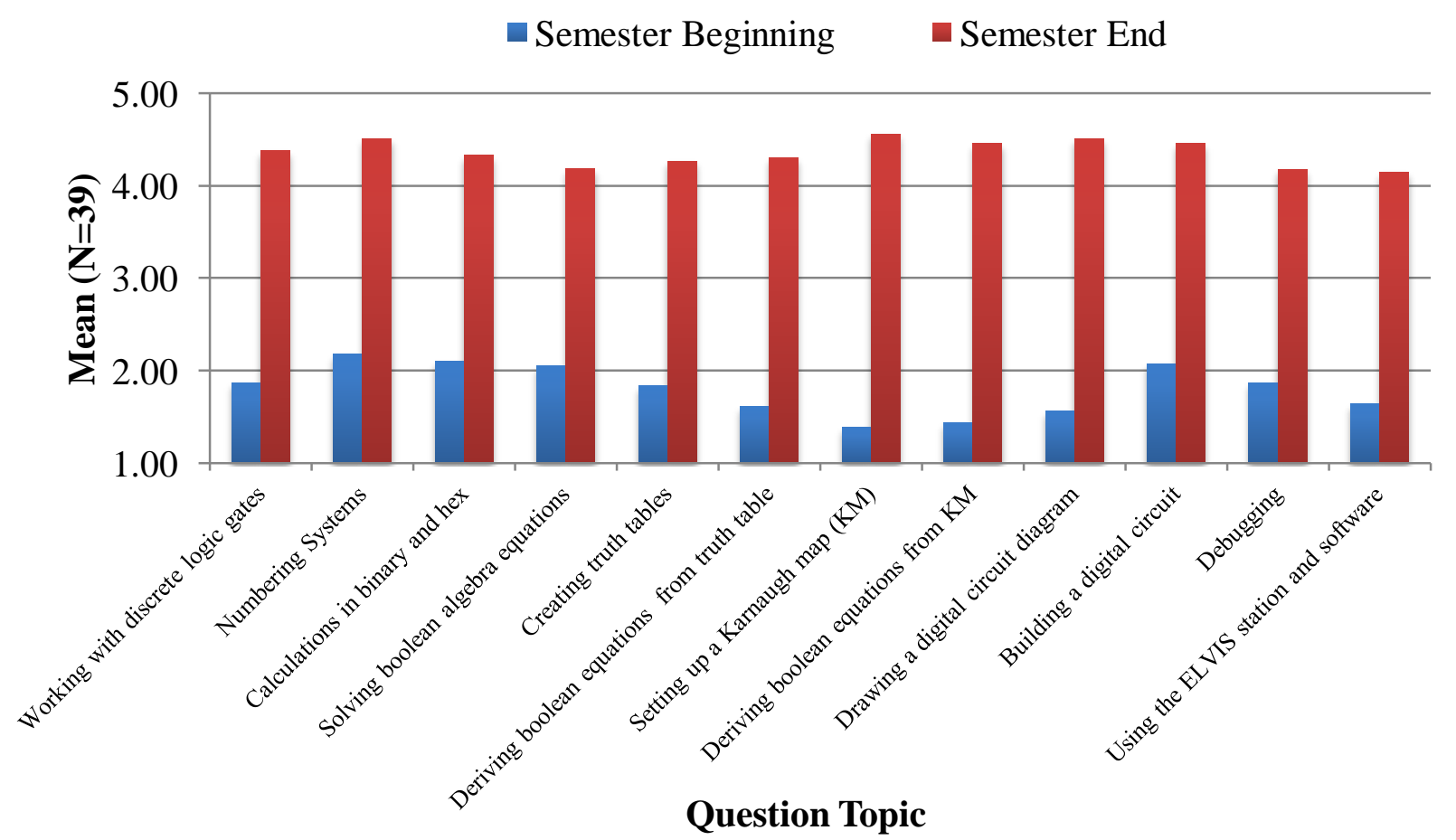

Figure 4. Self-reported confidence data related to skills covered in digital logic project on Likert scale (1-5).

It is often the case in project-based courses that students will work on a project that they really enjoy, but then end up not feeling as though they have truly learned anything. In this case, they 
may have been motivated to work on the project but afterwards they do not feel any closer to being an engineer than when they started. The opposite can also be true. They may feel that they have learned the material, but they simply did not enjoy the work and were not at all motivated to really apply themselves. Therefore, the authors wanted to survey the students on how they valued the project in two different ways. Again, having a project so heavy in electrical theory, it was feared that a multi-disciplinary group may either not enjoy working on the project or may not apply themselves enough to learn the material well. The worst-case scenario would have been if both were true. Fortunately, the data showed that students both enjoyed working on the ALU project and also felt that they had learned a great deal after completing it (see Figure 5).

\section{Educational v. Enjoyment Value of Digital Logic Project}

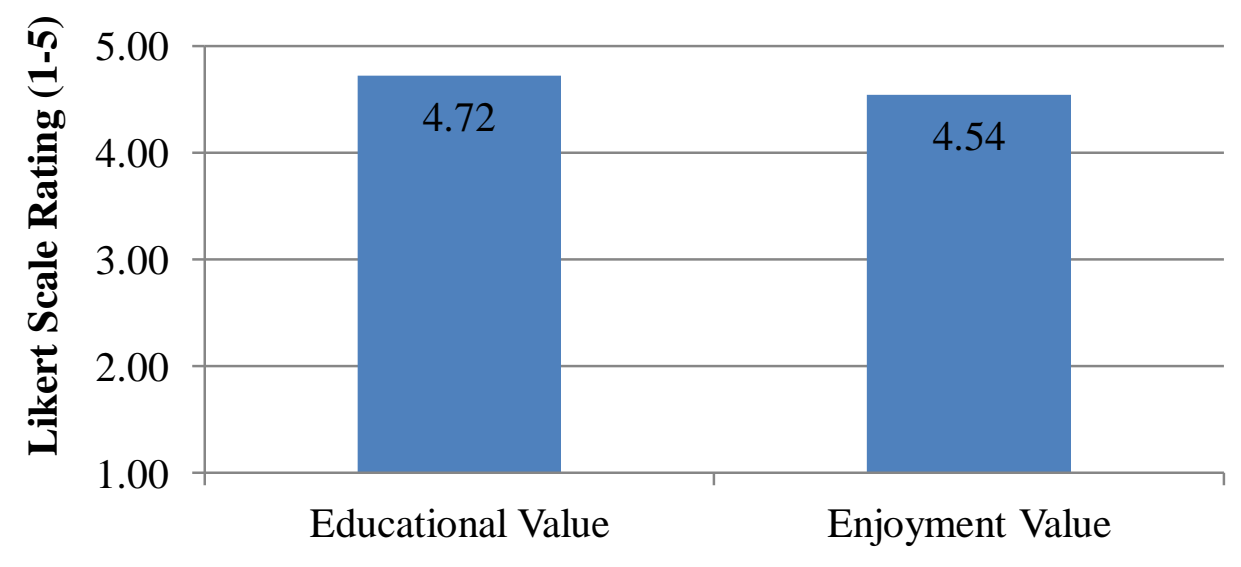

Value Type

Figure 5. Student perceptions of education value of project versus their enjoyment level. (Spring 2011) Responses based on a 5-point Likert scale.

Finally, responses from open-ended questions about what students liked and disliked about the class were analyzed for information about the students' attitudes towards the digital logic project. From those responses, 27 were positive remarks related to the project or the hands-on lab work in general. Fifteen of those specifically mentioned that they enjoyed working on the digital logic project and that it was one of their favorite things about the course. The students conveyed a sense of great accomplishment in having built something with their hands and appreciated the opportunity to learn by doing.

- "The gratification of having successfully completed a project and having a technical 'thing' that I could point to and say 'I built that!'”

- "Getting to work hands-on with real engineering projects, not just listening or writing about something."

- "I actually feel confident in making an ALU, from beginning (design) to end (construction). That is why I enjoyed it."

- "[We were] translating a project from paper to applicable projects."

- "I learn actively, and by physically working on something I learned better."

- "We could test it, feel it, touch it." 
The students also liked the fact that they were being challenged in this project, and that it showed them how to break down large tasks into a series of small testable steps.

- "The $[\mathrm{ALU}]$ was fun yet difficult enough to keep my attention."

- "It broke down the logic into doable circuit building."

- "It was much more open-ended problem solving than the other projects."

- "I liked the ALU...I rarely had points where I couldn't figure it out. It took a lot of time, but it allowed for the greatest amount of problem-solving."

- "I liked lab work because it was fun and challenging while having a clear goal."

One of the major concerns about introducing this ALU project into a mostly non-ECE group was that the students would complain about the lack of diversity or relevance of the course content. Surprisingly, there were only four student comments reflecting such a view. Other unfavorable comments referred mostly to the amount of time provided for course projects. (There were 4 projects in all for a 15-week course.) Despite those particular student concerns, the overall response from students regarding the course was very favorable, meaning that the introduction of the digital logic project did not have a significant negative impact on either student cognitive or affective outcomes and in fact appeared to have a significant positive impact.

\section{References}

1 Wood, S. L. in Frontiers in Education Conference, 1994. Twenty-fourth Annual Conference. Proceedings. 388-392.

2 Chia-Jeng, T. Digital System Design Using Microarchitectural Modeling. Education, IEEE Transactions on 51, 93-99, doi:10.1109/TE.2007.906604 (2008).

3 Roppel, T. A., Hung, J. Y., Wentworth, S. W. \& Hodel, A. S. An interdisciplinary laboratory sequence in electrical and computer engineering: curriculum design and assessment results. Education, IEEE Transactions on 43, 143-152, doi:10.1109/13.848066 (2000).

4 Cordes, D. et al. in Frontiers in Education Conference, 1997. 27th Annual Conference. Teaching and Learning in an Era of Change. Proceedings. 1354-1358 vol.1353.

5 Puvvada, G. \& Breuer, M. A. Teaching computer hardware design using commercial CAD tools. Education, IEEE Transactions on 36, 158-163, doi:10.1109/13.204837 (1993).

6 Uribe, R. B., Haken, L. \& Loui, M. C. A design laboratory in electrical and computer engineering for freshmen. Education, IEEE Transactions on 37, 194-202, doi:10.1109/13.284994 (1994).

7 Hall, D. V. Teaching design methodology and "industrial strength" EDA tools in a first-term freshman digital logic course. Education, IEEE Transactions on 41, 45-49, doi:10.1109/13.660787 (1998).

8 Reisslein, M., Tylavsky, D., Matar, B., Seeling, P. \& Reisslein, J. in Frontiers In Education Conference - Global Engineering: Knowledge Without Borders, Opportunities Without Passports, 2007. FIE '07. 37th Annual. S4A-1-S4A-6.

9 Alciatore, D. G. \& Histand, M. B. Mechatronics at Colorado State University. Mechatronics 5, 799810, doi:10.1016/0957-4158(95)00051-6 (1995).

10 Director, S. W., Khosla, P. K., Rohrer, R. A. \& Rutenbar, R. A. Reengineering the curriculum: design and analysis of a new undergraduate Electrical and Computer Engineering degree at Carnegie Mellon University. Proceedings of the IEEE 83, 1246-1269, doi:10.1109/5.406429 (1995).

11 Eris, O. et al. in Proceedings of the American Society for Engineering Education Conference and Exposition. 


\section{Appendix A: Spring 2011 ENG 1331H Survey Questions}

\section{ENG 1331H End-of-Semester Evaluation}

\section{Spring 2011}

*** If there are any questions that don't apply to you, simply leave the question blank.

\begin{tabular}{|c|c|c|c|c|c|c|c|c|c|c|c|}
\hline & $\begin{array}{l}\text { Please rate your knowledge of the following } \\
\text { topics at the beginning of the ENG } 1331 \mathrm{H} \text { course }\end{array}$ & Beq & nnin & of th & Sen & ster & & d c & he & nes & \\
\hline MY KNOV & ILEDGE OF & low & & & & high & low & & & & high \\
\hline 1 & the practice of engineering & 1 & 2 & 3 & 4 & 5 & 1 & 2 & 3 & 4 & 5 \\
\hline 2 & career options in engineering & 1 & 2 & 3 & 4 & 5 & 1 & 2 & 3 & 4 & 5 \\
\hline 3 & electronics & 1 & 2 & 3 & 4 & 5 & 1 & 2 & 3 & 4 & 5 \\
\hline 4 & electronics laboratory equipment & 1 & 2 & 3 & 4 & 5 & 1 & 2 & 3 & 4 & 5 \\
\hline 5 & data collection procedures & 1 & 2 & 3 & 4 & 5 & 1 & 2 & 3 & 4 & 5 \\
\hline 6 & research procedures & 1 & 2 & 3 & 4 & 5 & 1 & 2 & 3 & 4 & 5 \\
\hline 7 & laboratory notebook keeping & 1 & 2 & 3 & 4 & 5 & 1 & 2 & 3 & 4 & 5 \\
\hline 8 & $\begin{array}{l}\text { engineering documentation (e.g., MATLAB } \\
\text { portfolio) }\end{array}$ & 1 & 2 & 3 & 4 & 5 & 1 & 2 & 3 & 4 & 5 \\
\hline 9 & technical writing & 1 & 2 & 3 & 4 & 5 & 1 & 2 & 3 & 4 & 5 \\
\hline 10 & the engineering design process & 1 & 2 & 3 & 4 & 5 & 1 & 2 & 3 & 4 & 5 \\
\hline 11 & programming & 1 & 2 & 3 & 4 & 5 & 1 & 2 & 3 & 4 & 5 \\
\hline 12 & logical operators (AND, OR, NOT) & 1 & 2 & 3 & 4 & 5 & 1 & 2 & 3 & 4 & 5 \\
\hline 13 & $\begin{array}{l}\text { programming structures (conditional statements, } \\
\text { loops, switch statements) }\end{array}$ & 1 & 2 & 3 & 4 & 5 & 1 & 2 & 3 & 4 & 5 \\
\hline
\end{tabular}




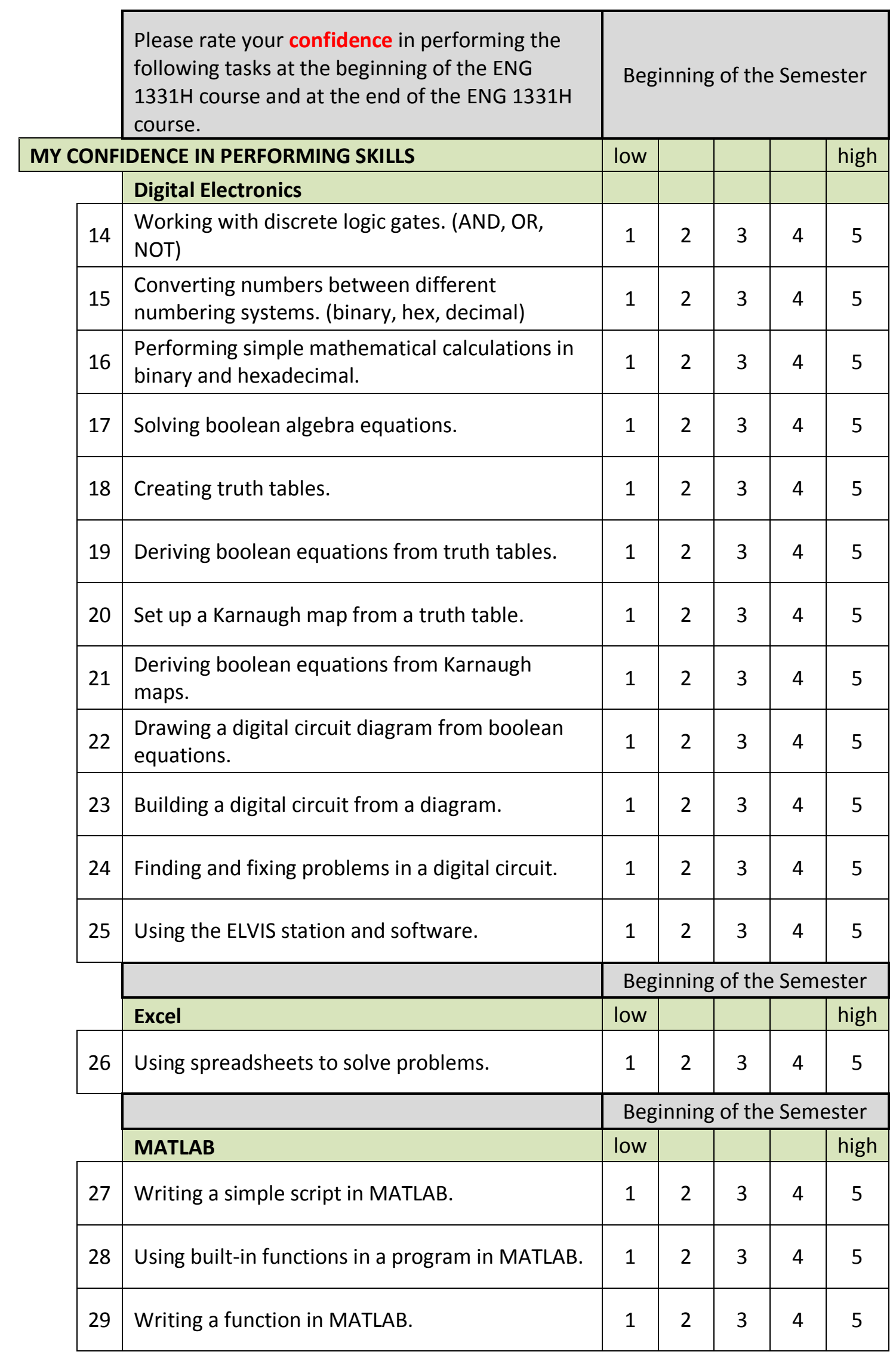

\begin{tabular}{|c|c|c|c|c|}
\hline \multicolumn{5}{|c|}{ End of the Semester } \\
\hline low & & & & high \\
\hline 1 & 2 & 3 & 4 & 5 \\
\hline 1 & 2 & 3 & 4 & 5 \\
\hline 1 & 2 & 3 & 4 & 5 \\
\hline 1 & 2 & 3 & 4 & 5 \\
\hline 1 & 2 & 3 & 4 & 5 \\
\hline 1 & 2 & 3 & 4 & 5 \\
\hline 1 & 2 & 3 & 4 & 5 \\
\hline 1 & 2 & 3 & 4 & 5 \\
\hline 1 & 2 & 3 & 4 & 5 \\
\hline 1 & 2 & 3 & 4 & 5 \\
\hline 1 & 2 & 3 & 4 & 5 \\
\hline 1 & 2 & 3 & 4 & 5 \\
\hline \multicolumn{5}{|c|}{ End of the Semester } \\
\hline low & & & & high \\
\hline 1 & 2 & 3 & 4 & 5 \\
\hline \multicolumn{5}{|c|}{ End of the Semester } \\
\hline low & & & & high \\
\hline 1 & 2 & 3 & 4 & 5 \\
\hline 1 & 2 & 3 & 4 & 5 \\
\hline 1 & 2 & 3 & 4 & 5 \\
\hline
\end{tabular}




\begin{tabular}{|l|l|c|c|c|c|c|c|}
\hline 30 & Creating graphical displays in MATLAB. & 1 & 2 & 3 & 4 & 5 \\
\hline 31 & $\begin{array}{l}\text { Performing mathematical calculations in } \\
\text { MATLAB. }\end{array}$ & 1 & 2 & 3 & 4 & 5 \\
\hline 32 & Creating a flowchart for a given algorithm. & 1 & 2 & 3 & 4 & 5 \\
\hline 33 & Writing a research question. & \multicolumn{2}{|c|}{ Beginning of the Semester } \\
\hline & Qualitative Research & low & & & & high \\
\hline 34 & Designing a research study. & 1 & 2 & 3 & 4 & 5 \\
\hline 35 & Writing a research proposal. & 1 & 2 & 3 & 4 & 5 \\
\hline 36 & Collecting research data. & 1 & 2 & 3 & 4 & 5 \\
\hline 37 & Performing semi-structured interviews. & 1 & 2 & 3 & 4 & 5 \\
\hline 38 & $\begin{array}{l}\text { Interpreting research data. (i.e., making valid } \\
\text { conclusions from your data) }\end{array}$ & 1 & 2 & 3 & 4 & 5 \\
\hline 39 & Writing a technical journal article. & 1 & 2 & 3 & 4 & 5 \\
\hline 40 & Creating a research poster. & 3 & 4 & 5 \\
\hline
\end{tabular}

\begin{tabular}{|c|c|c|c|c|}
\hline 1 & 2 & 3 & 4 & 5 \\
\hline 1 & 2 & 3 & 4 & 5 \\
\hline 1 & 2 & 3 & 4 & 5 \\
\hline \multicolumn{5}{|c|}{ End of the Semester } \\
\hline low & & & & \multicolumn{1}{|c|}{ high } \\
\hline 1 & 2 & 3 & 4 & 5 \\
\hline 1 & 2 & 3 & 4 & 5 \\
\hline 1 & 2 & 3 & 4 & 5 \\
\hline 1 & 2 & 3 & 4 & 5 \\
\hline 1 & 2 & 3 & 4 & 5 \\
\hline 1 & 2 & 3 & 4 & 5 \\
\hline 1 & 2 & 3 & 4 & 5 \\
\hline 1 & 2 & 3 & 4 & 5 \\
\hline
\end{tabular}

Please rate the impact of this course.

Please use the following scale for your answers where appropriate:

Strongly Disagree (SD), Disagree (D), Neutral (N), Agree (A), Strongly Agree (SA)

\begin{tabular}{|c|c|c|c|c|c|c|}
\hline \multicolumn{2}{|c|}{ COURSE IMPACT } & \multirow[b]{2}{*}{ SD } & \multirow[b]{2}{*}{$D$} & \multirow[b]{2}{*}{$\mathrm{N}$} & \multirow[b]{2}{*}{ A } & \multirow[b]{2}{*}{ SA } \\
\hline & & & & & & \\
\hline 41 & $\begin{array}{l}\text { This course has increased my commitment to } \\
\text { become an engineer. }\end{array}$ & 1 & 2 & 3 & 4 & 5 \\
\hline 42 & $\begin{array}{l}\text { This course has discouraged me from wanting to } \\
\text { be an engineer. }\end{array}$ & 1 & 2 & 3 & 4 & 5 \\
\hline 43 & $\begin{array}{l}\text { The skills obtained in this course will help me in } \\
\text { other classes. }\end{array}$ & 1 & 2 & 3 & 4 & 5 \\
\hline 44 & $\begin{array}{l}\text { Participating in this class has increased my } \\
\text { confidence in my abilities as an engineer. }\end{array}$ & 1 & 2 & 3 & 4 & 5 \\
\hline 45 & $\begin{array}{l}\text { As a result of this class, I am thinking of changing } \\
\text { my major to another engineering discipline. }\end{array}$ & 1 & 2 & 3 & 4 & 5 \\
\hline
\end{tabular}




\begin{tabular}{|c|l|c|c|c|c|c|}
46 & $\begin{array}{l}\text { As a result of this class, I am thinking of changing } \\
\text { my major to something other than engineering. }\end{array}$ & 1 & 2 & 3 & 4 & 5 \\
\hline 47 & $\begin{array}{l}\text { As a result of this class, I have formed a new } \\
\text { study group within the Honors Engineering } \\
\text { Program (HEP). }\end{array}$ & 1 & 2 & 3 & 4 & 5 \\
\hline 48 & $\begin{array}{l}\text { As a result of this class, I have formed new } \\
\text { friendships within the Honors Engineering } \\
\text { Program (HEP). }\end{array}$ & 1 & 2 & 3 & 4 & 5 \\
\hline
\end{tabular}

\begin{tabular}{|c|c|c|c|c|c|c|}
\hline \multirow[b]{2}{*}{49} & \multicolumn{6}{|c|}{$\begin{array}{l}\text { Please rate the following activities/projects based on their educational value, } \\
\text { where } 5 \text { would indicate that the activity/project was very educational and } 1 \\
\text { would indicate that the activity/project was not at all educational. }\end{array}$} \\
\hline & Digital Logic, 2-bit ALU Project & 1 & 2 & 3 & 4 & 5 \\
\hline 50 & Excel Resistor Decoder & 1 & 2 & 3 & 4 & 5 \\
\hline 51 & MATLAB Image Processing Project & 1 & 2 & 3 & 4 & 5 \\
\hline 52 & Qualitative Research Project & 1 & 2 & 3 & 4 & 5 \\
\hline
\end{tabular}

\begin{tabular}{|c|c|c|c|c|c|c|}
\hline \multirow[b]{2}{*}{53} & \multicolumn{6}{|c|}{$\begin{array}{l}\text { Please rate the following activities/projects based on how much you enjoyed } \\
\text { completing them, where } 5 \text { would indicate that you very much enjoyed the } \\
\text { activity/project and } 1 \text { would indicate that you did not enjoy the } \\
\text { activity/project at all. }\end{array}$} \\
\hline & Digital Logic, 2-bit ALU Project & 1 & 2 & 3 & 4 & 5 \\
\hline 54 & Excel Resistor Decoder & 1 & 2 & 3 & 4 & 5 \\
\hline 55 & MATLAB Image Processing Project & 1 & 2 & 3 & 4 & 5 \\
\hline 56 & Qualitative Research Project & 1 & 2 & 3 & 4 & 5 \\
\hline
\end{tabular}

\section{Open-ended Questions}

57 What was your favorite aspect of this course?

Explain why? 
58 What was your least favorite aspect of this course? Explain why?

59 Now that you have completed this course, do you have any suggestions for future offerings of ENG $1331 \mathrm{H}$ ? (e.g., changes/additions to the content? new projects? rooms? equipment? anything?) 